\title{
UN PROYECTO ESPAÑOL ANÓNIMO (1852) DE LENGUA UNIVERSAL
}

\author{
María Luisa Calero Vaquera \\ Universidad de Córdoba
}

Según Louis Couturat y Léopold Leau ${ }^{1}$, el primer proyecto completo ${ }^{2}$ de lengua universal (en adelante LU) elaborado con un procedimiento a posteriori, es decir, sobre la base de las lenguas naturales, es el denominado Communicationssprache (= 'lengua de comunicación'), dado a conocer en 1839 por el alemán J. Schipfer, quien toma prestadas del francés la mayor parte de las piezas léxicas que integran ese nuevo idioma. Se trata, pues, de un ensayo precedente de aquellos otros que en años sucesivos intentaron formar un idioma común sobre el modelo exclusivo de una sola lengua natural $^{3}$.

\footnotetext{
${ }^{1}$ En su obra Histoire de la langue universelle, Paris, Librairie Hachette et $C^{\mathrm{ie}}, 1907,2 .^{\mathrm{a}}$ ed.

${ }^{2}$ El estudio titulado «Langue nouvelle» y publicado en la Encyclopédie de Diderot y D'Alembert (usamos la ed. de 1765, Neufchastel, Chez Samuel Faulche \& Compagnie, Libraires \& Imprimeurs, t. IX, págs. 21-24) por M[onsieur] Faiguet, es considerado por Couturat y Leau (op. cit., págs. 239-240) una «première idée d'une langue a posteriori», un simple esbozo en el que, en efecto, sólo se nos presenta un modelo de conjugación verbal, así como el procedimiento que debe seguirse en la expresión de las declinaciones, la manera de formar aumentativos y diminutivos, un cuadro con el sistema pronominal y la denominación de los números. Umberto Eco, en La ricerca della lingua perfetta nella cultura europea, Roma-Bari, Editori Laterza, 1993, pág. 346 [trad. española: Barcelona, Crítica, 1994], estima, por su parte, que «la palma dell'anzianitá spetta probabilmente a un progetto che appare sotto lo pseudonimo di Carpophorophilus nel 1734», sin facilitar más datos.

${ }^{3}$ El proyecto de José López Tomás, titulado Lengua española universal (Valladolid, Imprenta Castellana, 1918), coincide con el de J. Schipfer en escoger una sola lengua (en este caso la española) para, con ciertas modificaciones, ser usada como vehículo de comunicación internacional (vide nuestro trabajo «El proyecto de Lengua española universal (1918) de J. López Tomás», en A. León Sendra y V. López Folgado, eds., In Memoriam Henry Sweet, [Córdoba] Grupo de Investigación de la Junta de Andalucía n. ${ }^{\circ}$ 5075; vol. 1, págs. 24-35). Poco después, Charles K. Ogden, en BASIC English, London, The Orthological Institute, 1930 [nueva ed.: London, Kegan Paul Trench Trubner and Company, 1944], propone como lengua de intercambio científico y comercial un inglés notablemente simplificado en su gramática y vocabulario.
} 
El proyecto que, también fundado en un criterio a posteriori (si bien sobre la base de varias lenguas), registran a continuación los citados autores franceses es el Pantos-dimou-glossa (= 'lengua de todos los pueblos'), y se debe al profesor de lenguas Lucien de Rudelle. Tal tentativa, publicada en 1858 , no es, en efecto, sino el resultado de la combinación de varios idiomas: el griego, el latín y las lenguas neolatinas, además del inglés, alemán y ruso. Este tipo de sistemas, cuyas estructuras léxicas y gramaticales se extraen, en mayor o menor grado, de los elementos compartidos por los idiomas europeos de más difusión, se acercan al ideal de internacionalidad soñado por los inventores de LU: al estar basados en un criterio realista, relativamente alejado de los afanes racionalizadores que caracterizaban a otros intentos más primitivos, su propagación y adopción podía ser, al menos teóricamente, más factible. Asimismo, estas lenguas híbridas, junto con aquellas (arriba mencionadas) que toman como base un solo sistema lingüístico, suponen un salto cualitativo con relación a los proyectos elaborados a priori: aquéllos que, sin soporte en las lenguas naturales (por su supuesta condición de códigos plagados de anomalías e imprecisiones), adoptaban como único norte en su formación la más pura racionalidad, inevitablemente alejada de la realidad de las lenguas.

No obstante, podemos afirmar que la aparición de este grupo de LU, cuya peculiaridad reside en un método de elección de sus unidades léxicas basado en el criterio de la internacionalidad de las mismas, puede retrotraerse a 1852 , año en que se publica, en la imprenta de José M. Esper de Sanlúcar de Barrameda, la obrita anónima Del idioma universal, sus ventajas, y posibilidad de obtenerlo. Incluso podría adelantarse en casi treinta años más el descubrimiento del nuevo método si concedemos crédito a las declaraciones del propio autor, quien asegura que «a principios del año de 1824 [...] concebimos las primeras ideas de este asunto» ${ }^{4}$, aclarando en nota: «Motivos ajenos a nuestra voluntad, que no interesan al público, nos han impedido redactar antes este breve opúsculo» ${ }^{5}$. La relevancia de este libro de autor desconocido $-\mathrm{y}$ adelantamos conclusiones - no se cifra en la coherencia o en la brillantez de sus propuestas lingüísticas, más bien faltas de tales cualidades, sino en el hecho de tratarse del primer proyecto que conocemos en el que se bosqueja una LU ideada sobre la base de las principales lenguas europeas, pronta antecesora, pues, de los célebres Volapük (1880) y Esperanto (1887).

Pero hasta ahora no se le había reconocido este mérito, ni ningún otro, a este ensayo, que, como ha lamentado Manuel Mourelle-Lema ${ }^{6}$, «desco-

\footnotetext{
${ }^{4}$ Anónimo, op. cit., art. 11.

5 Ibid., pág. 7.

${ }^{6}$ En La teoría lingüistica en la España del siglo XIX, Madrid, Prensa Española, 1968, pág. 147.
} 
nocieron Couturat y Leau al historiar la literatura desplegada en torno de la lengua universal» ${ }^{7}$. $\mathrm{Al}$ margen del apresurado análisis que de esta obra nos ofrece Mourelle-Lema ${ }^{8}$, los únicos comentarios que sobre ella hemos podido hallar se encuentran en el Boletín de la Sociedad de Lengua Universal ${ }^{9}$, donde asimismo se reprodujo parte del texto anónimo, que mereció el siguiente juicio del director del Boletín, Lope Gisbert: «Algunas buenas ideas generales se encuentran en el prefacio; pero el proyecto no merece tomarse en consideración» ${ }^{10}$.

1. Previo al estudio de su contenido, merece un espacio la cuestión de la autoría de tan precoz obra. Pedro Mata fue el primero en desvelar la (supuesta) identidad de su autor:

[...] el Sr. D. Pedro López Martínez, si no estoy equivocado, publicó en San Lúcar de Barrameda [sic] en 1852 un proyecto de lengua universal o unas bases para ella, tomando las rádicales de las lenguas más conocidas $[\ldots]^{11}$.

Mourelle-Lema, sin duda por una lectura errónea del citado texto, declara que el autor es «Pedro Martínez López, uno de los enemigos más descarados de Vicente Salvá; y gramático como éste» ${ }^{12}$. Ante la posibilidad de que el dato incorrecto fuera el proporcionado por Mata (dado que conocemos la existencia de Pedro Martínez López en la historia de la lingüística española, no así la de López Martínez), optamos por cotejar el trabajo que nos ocupa, Del idioma universal..., con el más conocido (y relativamente cercano en el tiempo a aquél) de Martínez López: los Principios de la lengua castellana (1841) ${ }^{13}$. Una somera lectura comparativa de ambas obras nos permitió advertir ya serias desemejanzas doctrinales entre una y otra; como muestra:

- La ordenación que sigue el autor anónimo en su exposición gramatical es la establecida por la Real Academia Española, y así lo reconoce ex-

\footnotetext{
7 También se echa en falta la inclusión de este proyecto entre los de autoría española estudiados por Julián Velarde Lombraña en su artículo «Proyectos de lengua universal ideados por españoles», Taula (Quaderns de Pensament), 7-8, 1987, págs. 7-78.

${ }^{8}$ Cf. su op. cit., págs. 147-150.

9 Publicado en Madrid, Imprenta de El Clamor Público, 1. época (n. $\left.{ }^{\text {os }} 1-15\right)$ : 1861-1864; 2 . $^{\text {a }}$ época (n. ${ }^{\circ}$ 1): 1866. Los comentarios a que nos referimos se encuentran en el n. ${ }^{\circ}$ 3, 1862, pág. 72.

${ }_{10}$ Otras breves referencias, y en un tono no más favorable, pueden hallarse en el n. ${ }^{\circ} 13$ del mismo Boletín (1864, pág. 28), así como en Pedro Mata, Curso de lengua universal. Lecciones dadas en el Ateneo Centífico y Literario de Madrid, Madrid, Librería de León Pablo Villaverde, pág. 317 [2.a ed.: Buenos Aires, 1886].

${ }_{11}$ P. Mata, op. cit., pág. 317.

12 M. Mourelle-Lema, op. cit., pág. 147.

13 ... o prueba contra todos los que asienta D. Vicente Salvá en su Gramática, Madrid, Librería de la Señora Viuda de Calleja e Hijos, 1841, 2.a ed.
} 
presamente ${ }^{14}$; de manera que las categorías gramaticales tratadas son coincidentes en número, denominación y orden con las enseñanzas académicas de la época, a saber: artículo, nombre, adjetivo, pronombre, verbo, participio, adverbio, preposición, conjunción e interjección. Sólo en la catalogación de los tiempos verbales el anónimo se despega en parte de su modelo, al introducir, junto a la denominación académica, un segundo rótulo (presente indefinido, presente definido anterior simple...) dictado por $\mathrm{N}$. Beauzée y R. A. Sicard ${ }^{15}$. Por su parte, y de forma contrapuesta, Martínez López reduce a siete las partes de la oración (el pronombre y el artículo se incluyen, respectivamente, en las clases sustantiva y adjetiva; el participio no constituye clase independiente del verbo), adoptando en la conjugación verbal una nomenclatura de los tiempos (y una distribución de los modos) muy alejada de la propuesta por el anónimo.

- Un nuevo argumento - esta vez de tipo ortográfico- viene a menguar las posibilidades de que bajo el anónimo autor de Del idioma universal... se esconda el nombre de Martínez López: en el citado libro se utiliza sistemáticamente el grupo consonántico $c s$ para representar la pronunciación del grafema $x$ (práctica no infrecuente en la época). Oigamos la opinión que a Martínez López le merece tal proceder: «Es un despropósito el querer que, acompañando a la $s$, remplace a la $\mathrm{X}$; es no conocer siquiera el valor de esta letra, ni la verdadera pronunciación de aquélla» ${ }^{16}$.

Tras estas observaciones, que nos han permitido constatar graves discordancias entre las dos obras confrontadas, parece improcedente seguir manteniendo la hipótesis de que ambas salieron de la pluma del mismo autor.

Con los escasos datos que poseemos resulta aventurado proponer un nuevo antropónimo para rellenar con verosimilitud la laguna de autoría que padece este revolucionario proyecto de LU fechado en 1852. No obstante, creemos razonable suponer que su autor (que bien podría llevar el nombre de Pedro López Martínez) fuera uno de los numerosos intelectuales que, con la vuelta del absolutismo a España, emigraron en 1823 (recuérdese que el año en que se concibe este nuevo idioma es el de 1824) a otros países europeos, donde el choque con nuevos hábitos lingüísticos constituiría un

\footnotetext{
14 «Nos hemos guiado principalmente para el orden seguido por la gramática de la Academia Española, sin más variaciones que muy pocas reclamadas por necesidad imprescindible» (Anónimo, op. cit., pág. 26).

15 «[En la conjugación verbal] señalaremos los tiempos con dos títulos, siendo el primero el que han tenido en las gramáticas usuales, y el segundo el más filosófico propuesto por autores modernos, en lo que hemos seguido los preceptos de Beauzée y Sicard...» (Anónimo, op. cit., pág. 19, nota).

${ }^{16}$ P. Martínez López, op. cit., pág. 146; puede verse también pág. 172.
} 
excelente caldo de cultivo para la tarea de construcción de un idioma que acabara con las barreras lingüísticas ${ }^{17}$.

2. El libro anónimo aparece dividido en dos partes: la primera, con una extensión de veinte páginas, lleva por título el mismo que figura al frente de la portada: Del idioma universal, sus ventajas, y posibilidad de obtenerlo; la segunda, más extensa (cincuenta y seis páginas) y titulada Bosquejo de gramática del idioma universal, incluye, tras una advertencia preliminar, una aplicación práctica de los principios teóricos expuestos en la primera parte. Repasaremos sus contenidos en las líneas que siguen.

2.1. Se inicia el primer fragmento con una valoración de la facultad del lenguaje, al que califica como «don preciosísimo» y «fundamento de toda la civilización» (art. 1) ${ }^{18}$, apoyando sus argumentos en algunos gramáticos filósofos franceses (E. B. de Condillac; A. Destutt de Tracy...) que consideran esta capacidad humana como poderoso motor del progreso del conocimiento. Se destaca la necesidad que determinadas personas tienen (diplomáticos, comerciantes, viajeros, etc.) de conocer «las principales lenguas que se hablan en Europa» (art. 5) (francés, inglés, alemán, ruso, italiano y español) a fin de garantizar sus relaciones internacionales, así como la dificultad de dominar tales idiomas por mucho estudio y empeño que se dedique a ello. Descartada esta alternativa («aprender muchas lenguas es imposible», art. 8) como medio de entendimiento universal, queda aún otra vía: «admitir por idioma general a uno de los mejores» (id.), solución de difícil factura, porque «teniendo todos los hombres mucho amor a su lengua patria, juzgarían los más que la suya debiera ser preferida» (id.). Por su parte, el latín, de árido estudio y reemplazado a la sazón por las lenguas modernas, se muestra incapaz de servir como vehículo de comunicación in-

\footnotetext{
17 También nos causa extrañeza la circunstancia de que, si bien concebido en 1824, el proyecto no llegara a publicarse hasta 1852 . Tal vez el anónimo autor, en contra de sus afirmaciones («hasta ahora nadie lo ha propuesto [un idioma universal]», op. cit., art. 11), llegó a conocer la edición del Proyecto y ensayo de una lengua universal y filosófica (Madrid, Imprenta de J. Martín Alegría, 1851) de Bonifacio Sotos Ochando (vide nuestro artículo «En torno a la lengua universal. La contribución de B. Sotos Ochando (1785-1869)», Revista Española de Lingüistica, 23/2, 1993, págs. 221-233), lo que instigaría a aquél a sacar a la luz su propio sistema, guiado por criterios bien diferentes; la premura con que se redactó la obra — parte de ella - así parece demostrarlo: «Esta equivocación [...] y alguna más que podrá descubrirse, han dependido de haber escrito casi toda la gramática al mismo tiempo que se imprimía, lo que no nos permitió revisar escrupulosamente el manuscrito hasta que mucha parte de él estaba ya impreso» (Anónimo, op. cit., pág. 80).

${ }^{18}$ La primera parte del libro divide su contenido en 77 artículos numerados correlativamente: a ese orden numérico (salvo indicación contraria) irán referidas nuestras citas para facilitar su localización.
} 
ternacional. Para lograr este propósito, a juicio de nuestro autor, sólo queda la opción de inventar una nueva lengua:

Puede conseguirse este grande objeto formando una lengua artificial, sencilla en sus elementos, fácil de aprender para todas las naciones, aun aquellas cuyas hablas no tienen el menor punto de semejanza con las de Europa; y que reúna todas las circunstancias recomendables de las lenguas principales, así vivas como muertas, careciendo de todos sus defectos (art. 10)

Considera una empresa realizable y útil la formación de una LU, aunque «hasta ahora nadie lo ha propuesto» [!] (art. 11). Frente a las irregularidades de los idiomas vivos, «nacidas de haberse compuesto sin plan por gente ignorante» (art. 12), la LU propugnada, al ser fruto de una «sabia combinación», carecerá de las anomalías y defectos de aquéllos; es la máxima aspiración de todos los inventores de lenguas, y el que nos ocupa no es una excepción:

No ofrecerá la menor irregularidad en sus géneros, plurales, ni en ninguna de las partes de la oración, como tampoco en las conjugaciones de los verbos, ni en la sintaxis; no empleará más vocales que las cinco que pueden llamarse primitivas, ni más consonantes que las precisas [...]; aspirará a la mayor concisión [...]; y disfrutará de ortografía sencillísima, que no se separe de la pronunciación [...] (art. 13).

A continuación enumera las etapas y requisitos que deberá satisfacer la realización del proyecto, pasaje en el cual se contiene una valiosa propuesta de "planificación lingüística», al coincidir con los establecidos por sociolingüistas actuales: 1) corresponderá a un «literato laborioso» o a una «corporación literaria» (reunida por propia iniciativa, o bien a instancias de un «Rey benéfico e ilustrado» o de «todos los soberanos de Europa») la decisión de formar una $\mathrm{LU}$, escogiendo una de entre las presentadas (= decisión politica, o selección/elección de un esquema lingüístico básico) ${ }^{19}$;2) se establecerá el «plan general» de la nueva lengua, determinando las condiciones de sencillez, racionalidad, etc., requeridas en todos sus niveles (= codificación $) ; 3)$ se confeccionarán diccionarios con el fin de inventariar el nuevo léxico formado, con o sin referencias a una segunda lengua, empresa que facilitará la traducción a la universal de obras literarias célebres (= elaboración del esquema lingüístico, requisito interpretado por Fer-

19 Vid. Einar Haugen, «Linguistics and language planning», en William Bright, ed., Sociolinguistics. Proceedings of the UCLA Sociolinguistic Conference, 1964, The Hague, Mouton, 1966 [reimp. 1971], págs. 50-71. 
guson como traducibilidad de lo codificado a cualquier otro código lingüístico, y viceversa) ${ }^{20}$; 4) una comisión se encargará de propagar y conservar la LU, mediante publicaciones periódicas y, sobre todo, su enseñanza en las escuelas (= instrumentalización del código por todos los usuarios y para todas las finalidades y funciones previsibles); 5) gracias a aquellas traducciones y al uso que de la nueva lengua (aprovechando su universalidad) realizarán los literatos para difundir sus creaciones, se propiciará el aspecto estético de la misma (= cultivo del código) ${ }^{21}$; y 6) se prevé un plazo razonable para introducir las enmiendas necesarias a la lengua resultante (= etapa de evaluación o «retroalimentación», prevista por si fuera necesario corregir las estrategias) ${ }^{22}$.

Se alude a la gran ventaja que proporcionaría el disponer de una LU: el mucho tiempo que los jóvenes ahorrarían en su propia formación, puesto que una vez implantada aquélla, el alumno «podrá dedicarlos [esos años de la juventud] útilmente al estudio de otras ciencias» (art. 40); es éste un manido argumento que tras ser esgrimido originariamente por Leibniz hemos escuchado en más de un inventor de lenguas. Otras ventajas de segundo orden: todos la hablarán y escribirán «sin gran trabajo con la mayor pureza, por estar libre de las dificultades que abundan en todas las demás lenguas» (art. 44); por su inalterabilidad ${ }^{23}$ «se entenderá perfectamente dentro de muchos siglos» (art. 45); presentará «un todo homogéneo», en contraposición a las lenguas naturales, «conjunto mal avenido» (art. 46) de voces de distinto origen idiomático. Y un rosario de consabidos adjetivos pone punto final a las cualidades que el autor estima deseables en la LU: será «a un mismo tiempo y sin la menor excepción, fácil, sencilla, concisa, exacta y dulce sin demasiada afeminación» [!] (art. 47).

Sin solución de continuidad pasa a enumerar una serie de desiderata de índole lingüística (y que serán puestos en práctica más adelante en el Bosquejo) que deben ser tenidos en cuenta en la elaboración de la LU:

\footnotetext{
${ }^{20}$ Cf. Charles A. Ferguson, «Language development», en Joshua A. Fishman et al., eds., Language problems of developing nations, 1968, págs. 27-35.

${ }_{21}$ Cf. J. V. Neustupny, «Basic types on treatment of language problems», Linguistic Communications, 1, 1970, págs. 77-98 [reimp. en Joshua A. Fishman, ed., Advances in language planning, The Hague/Paris, Mouton, 1974, págs. 37-48].

${ }^{22}$ Joan Rubin, «Evaluation and language planning», en J. Rubin y B. Jernudd, eds., Can language be planned? Sociolinguistic theory and practice for developing nations, Honolulu, East West Center \& University Press of Hawaii, 1971, págs. 217-252.

${ }^{23} \mathrm{La}$ lengua que se propone «no deberá con el tiempo presentar más innovación que la nomenclatura exigida por los nuevos objetos que vayan presentando las artes y adoptando las ciencias» (Anónimo, op. cit., art. 45).
} 
- Las v o c a le s serán «las cinco primitivas» (art. 48) del español, italiano y portugués; las c on s o n a n te s serán aquellas «de fácil pronunciación y usadas por todas las naciones» (art. 49), excluyéndose por consiguiente «las duras, guturales, aspiradas, nasales y compuestas» (id.) (se concretará más adelante, en $\$ 2.2 .2$, cuáles son los grafemas elegidos para formar el alfabeto de la $\mathrm{LU}$ );

- como máximo, las síl a b a s estarán formadas por tres consonantes, «por lo mucho que esto contribuye a la mayor claridad y suavidad de la pronunciación» (art. 65).

- las clases de palabras se distinguirán por algún medio (por su terminación, por la colocación del acento, etc.) ${ }^{24}$;

- no existirán más que tres g é n e r o s: masculino, femenino y neutro, este último para referirse a «todos los animales de sexo desconocido, y los objetos inanimados» (art. 25); y dos nú me ro s: singular y plural («reinará la regularidad más completa en la formación del plural», art. 58);

- el artículo definido expresará formalmente los tres géneros y los dos números; a su juicio, tales distinciones flexivas concederán claridad al discurso, y por ello le parece preferible esta opción antes que el procedimiento seguido por la lengua inglesa para la determinación del sustantivo (un solo artículo definido indeclinable);

- para la formación de los a djetivos presenta una alternativa: «serán todos del género neutro, como en el inglés, o tendrán sus tres terminaciones distintas para todos los géneros» (art. 55);

- el único requisito exigido para la expresión de los c o m parati vos, superlativos, aumentativos y diminutivos es la regularidad;

- en el capítulo de los pro nom bre s, propugna para dirigirse al interlocutor el uso exclusivo de la segunda persona del singular (español $t u ́$ ), «el cual nada tiene de impropio ni de ridículo como el vos y el usted que ha establecido la necia vanidad de los hombres» (art. 70);

- la regularidad que observarán todos los ve rbos (incluso los defectivos tendrán su conjugación completa) se estima una de las mayores ventajas de este idioma; las flexiones verbales «si fuesen admitidas, se dispondrán del modo más breve y sencillo» (art. 53); podría suprimirse, por superfluo, el modo subjuntivo, así como aquellos tiempos «que no sean de precisa necesidad» (id.);

\footnotetext{
${ }^{24}$ Es éste un mecanismo muy utilizado por los inventores de lenguas a priori; véase, por ejemplo, el Proyecto de una lengua universal (Madrid, Imprenta de J. Martín Alegría, 1862, 3. a ed., págs. 2-26) de B. Sotos Ochando, en cuyo sistema el número de sílabas y la letra final de cada vocablo permiten diferenciar la categoría gramatical a que pertenece.
} 
- la sencillez y la brevedad presidirán la formación de los a d ve rb i o s, "pudiendo los de cada clase [semántica] tener una sola terminación, u otro lazo común» (art. 56); igual regla será aplicable a las preposi ciones y conjunciones;

- en cuanto a las interjecciones, «habrá muy pocas y fijas, o no las habrá» (art. 61);

- la s in tax is - se dice lacónicamente- será «sencilla, uniforme e invariable» (art. 63);

- desde el punto de vista se mántico, son también escasas las indicaciones que se sugieren: no existirán polisemias ni sinonimias («ninguna voz debe significar dos o más cosas [...]. Tampoco deberá ningún objeto tener dos o más nombres» (art. 62); se prohíben los idiotismos y «las partículas de adorno u otras inútiles» (art. 64);

- la ortografía se prevé «completamente regular y sencilla» (art. 66).

Una serie de consideraciones finales cierra esta primera parte del libro, de las que entresacamos tres ideas que merecen algún comentario:

a) Expresa la conveniencia de reemplazar las actuales grafías de la escritura común por otros caracteres de tipo taquigráfico, cuya utilización permitiría «ahorrar las cuatro quintas partes del tiempo, y otro tanto del papel que aquélla necesita» (art. 75); es una propuesta que ya había sido realizada en el siglo XVII por John Wilkins ${ }^{25}$, así como por Sotos Ochando ${ }^{26}$ dos siglos después, con la diferencia de que el anónimo se limita a señalar que la nueva escritura habrá de ser «una taquigrafía clara y exac.ta, como la española sin abreviaturas, que no deje letras en claro» (id.), sin mayores precisiones, en tanto que Sotos esboza una peculiar simbología (cierto que con base en el sistema taquigráfico) de los fonemas vocálicos y consonánticos, posiblemente inspirada en los real characters que diseñó el obispo inglés (cuya propuesta de escritura se presenta mucho más elaborada y completa al considerar, además de la representación de las unidades fonológicas más simples, todas las combinaciones silábicas posibles).

b) Ciertamente ingenua es la creencia que el anónimo mantiene respecto a la implantación de la LU:

Obtenido que fuese este idioma por el medio auténtico propuesto, llegaría con el tiempo a ser el general de todo el mundo civilizado; y después de muy extendido y arraigado será posible que remplace algún día a todas las lenguas que ahora están en uso, a lo menos entre la gente culta (art. 72).

\footnotetext{
${ }^{25}$ En su monumental obra de 1668 titulada An essay towards a real character and a philosophical language, (ed. facsímil) Menston, The Scholar Press, 1968, pág. 376.

${ }^{26}$ En Gramática de la lengua universal, Madrid, Imprenta de J. Martín Alegría, 1863, pág. 48. [Nueva ed., adicionada con numerosas traducciones interlineales].
} 
Tal muestra de candidez contrasta con la actitud más realista de otros autores contemporáneos a él, que creen, sin embargo, en

[...] la posibilidad de tener una lengua común y universal, fácil, sencilla, sin ninguna irregularidad, que aceptada por los gobiernos y por los pueblos, dejando subsistir todos los idiomas establecidos, como sucedía en los siglos pasados con el latín en Occidente, uniese las aspiraciones de la humanidad $[\ldots]^{27}$.

No se trata de una lengua universal, que sea admitida como la lengua vulgar de todo el mundo y sobre las ruinas de los idiomas usados en cada país. Trátase sólo de una lengua que pueda ser entendida y hablada por un número mayor $o$ menor de personas $[\ldots]^{28}$.

Esta idea será corroborada cuarenta años más tarde por la Délégation pour l'adoption d'une langue auxiliaire internationale en el artículo $1 .^{\circ}$ de su «Declaración»:

Il y a lieu de faire le choix et de répandre l'usage d'une Langue auxiliaire internationale, destinée, non pas à remplacer dans la vie individuelle de chaque peuple les idiomes nationaux, mais à servir aux relations écrites et orales entre personnes de langues maternelles différentes ${ }^{29}$.

Obsérvese, además, en esta última cita el trueque habido en la adjetivación del sustantivo lengua: en lugar de lengua universal se prefiere la denominación de lengua a ux i li ar internacional, expresión que no deja ya lugar a dudas sobre el papel que está llamado a desempeñar el nuevo código lingüístico.

c) La relación de dependencia entre gramática general y lengua universal es puesta de relieve por el anónimo:

Además de tantos beneficios importantes que debe producir el proyectado idioma [...], no debemos omitir uno de primer orden, el de simplificar y perfeccionar la gramática general, dando fin a la discordia que sobre muchos puntos de ella reina hace bastantes años (art. 76);

la misma idea que encontramos expresada por Pedro Mata en las lecciones que sobre la LU dictó en el Ateneo de Madrid: «La lengua universal es hija legítima y forzosa de la gramática general» ${ }^{30}$. Como hemos expresado en

\footnotetext{
${ }^{27}$ Florencio Janer, La lengua universal. Cuestión internacional, Madrid/París, A. Durán/A. Durand, 1860, pág. 5; subrayado en el original.

${ }^{28}$ Alejandrino Menéndez de Luarca, Establecimiento de la lengua universal. Cuestión práctica, Madrid, Imprenta de T. Fortanet, 1860, págs. 4-5.

${ }_{29}$ Apud Louis Couturat, Pour la langue internationale, Coulommiers, Imprimerie Paul Brodard, 1903, pág. 31.

${ }^{30}$ P. Mata, op. cit., pág. 23.
} 
otro lugar, los intentos habidos fundamentalmente en los siglos XVII y XIX para construir una LU apriorística pueden considerarse como integrantes de la fase de aplicación práctica que sucede y complementa a una etapa previa de reflexión teórica sobre la virtual existencia de una gramática común a todos los seres humanos. Nuestro autor se integra, pues, en las filas de quienes defienden la íntima vinculación de ambos dominios (uno teórico, otro práctico), sólo que sigue mostrando cierta dosis de ingenuidad con su creencia de que el establecimiento de la Lu cancelará las discordias que en el terreno teórico (el de los principios de la gramática general) se presentan.

2.2. En la «advertencia preliminar» que abre el segundo fragmento del libro, el titulado Bosquejo de gramática del idioma universal, se compendia una serie de sustanciosas consideraciones que vamos a tratar de resumir en el párrafo siguiente.

2.2.1. El autor reconoce con modestia que su ensayo no es sino un «bosquejo», una "débil muestra» de una LU, y que su única pretensión es «llamar la atención de los filólogos y demás literatos de todas las naciones hacia este importante punto, confiando que muchos de ellos unirán sus esfuerzos a los nuestros para robustecer la opinión de la necesidad y conveniencia de una perfecta lengua cosmopolita» (pág. 25). Resultan llamativas las reiteradas disculpas por su osadía de proyectar un idioma artificial:

[...] estamos muy convencidos de nuestra falta de instrucción y suficiencia para el caso; lo que dejamos aquí consignado, para que ya que se nos note justamente de atrevidos, no se nos atribuya la presunción de que nos creemos y declaramos exentos (pág. 27).

Tales expresiones de prevención nos llevan a conjeturar que nuestro autor carecía de especiales conocimientos de teoría gramatical, máxime cuando declara haberse «guiado principalmente para el orden seguido por la gramática de la Academia española, sin más variaciones que muy pocas reclamadas por necesidad imprescindible» (pág. 26); como quedó dicho, esta hipótesis aleja la posibilidad de que la autoría de la obra corresponda a Martínez López, lingüista de sólida formación gramatical $y$, por otra parte, escasamente «academicista».

Sí, en cambio, parece conocer las particularidades gramaticales de algunas lenguas europeas, requisito imprescindible para un autor que se propone formar un nuevo idioma entresacando elementos comunes a varias lenguas naturales; de manera que a la hora de construir el sistema gramatical de la suya propia va optando entre los diferentes recursos formales que le ofrecen las variedades lingüísticas europeas. 
¿Cuáles son esos idiomas que le sirven de materia prima para formar su lengua artificial? (procedimiento que, como se dijo, concede a esta obra el privilegio de ser el primer ensayo que conocemos donde se inventa un sistema lingüístico a posteriori basado en el criterio de la internacionalidad):

La elección de las voces adoptadas para artículos, pronombres, adverbios, preposiciones, conjunciones y demás que forman la armazón de toda lengua, ha sido hecha con detenido examen de sus equivalentes en latín, italiano, español, francés, inglés y alemán (pág. 26).

Una lengua muerta y cinco vivas (con algunas referencias esporádicas al portugués) forman, pues, el sustento de este nuevo idioma, cuyo creador sólo nos ofrece un anticipo: su «armazón», es decir, el conjunto de las palabras que hoy llamamos «gramaticales», aquellas que, a diferencia de las «palabras léxicas», figuran sistemáticamente en las gramáticas y constituyen un número reducido y fijo del vocabulario total de una lengua. En efecto:

Faltan para completar este idioma, además de un corto número de adverbios de poco uso, algunos centenares de adjetivos, muchos de verbos, y no pocos miles de sustantivos: pero su designación no ofrecerá proporcionadamente tantas dificultades como la de las 500 voces o pocas más que aquí ofrecemos (pág. 27).

$\mathrm{Y}$ en cuanto a las normas que han regido la selección de los términos que se proponen:

[La elección de las voces ha sido hecha] dando la preferencia a la que hallábamos admitida en dos o más de estas seis lenguas, o a la más breve, o más suave, o más adaptada a nuestro plan. Entrando en él que dichas voces fuesen monosílabas, como deben serlo todas las de frecuente uso, y que las más de sus clases se distinguiesen por la uniformidad de sus terminaciones, condición muy propia para conocer sus destinos y aprenderlas con mayor facilidad [...] (pág. 26).

Tenemos, pues, que el primer requisito considerado en la formación del léxico es el de su internacionalidad, factor que confiere a este sistema la precocidad varias veces subrayada ${ }^{31}$; en segundo plano, la bre v e d a d, lo que le lleva a inclinarse por vocablos monosilábicos; el carácter «suave» de los mismos se ha de entender como la armonía y el equilibrio que, desde un punto de vista prosódico, debe presidir la combi-

\footnotetext{
${ }^{31}$ André Martinet señala que, para las lenguas artificiales que surgen bien avanzada la segunda mitad del siglo XIX, «l'internationalité des formes devient le critère décisif de la valeur des différents projets»; vid. «La linguistique et les langues artificielles», Word, 2/I, 1946, págs. 37-47.
} 
nación de vocales y consonantes; por último, un criterio ho m o g e n e i $\mathrm{zad}$ or para las terminaciones de las palabras pertenecientes a la misma categoría gramatical, con el fin de identificar su función («sus destinos») en la frase.

Comoquiera que una de las premisas enumeradas, el monosilabismo léxico, no siempre se encuentra en las lenguas naturales que sirven de base al nuevo idioma, y mucho menos la uniformidad de la terminación categorial, confiesa que tal circunstancia «nos precisó en muchos casos a modificarlas [las palabras] o suplirlas con otras nuevas de nuestra invención» (pág. 26). Esta afirmación introduce un importante grado de apriorismo en el quehacer del autor anónimo y aproxima su proyecto de lengua a los que Couturat y Leau denominaban «sistemas mixtos» ${ }^{32}$, como el Volapük y otros de él derivados, que, por una parte, extraen su vocabulario de las radicales léxicas de las lenguas naturales y, por otra, modifican a capricho tales elementos para no favorecer a ninguna de ellas. Si bien no creemos adecuado hacer un grupo aparte con tales «sistemas mixtos» (puesto que siempre se da un cierto grado de apriorismo en cualquier sistema artificial construido a posteriori), sí nos vemos obligados a reconocer que el proyecto que nos ocupa presenta mayor arbitrariedad en la elección de su vocabulario que otros sistemas a posteriori que le suceden en el tiempo (por ejemplo, el Esperanto). Todo lo cual parece obedecer unas leyes lógicas: la transición desde las lenguas apriorísticas hasta aquellas que siguen un criterio a posteriori no se produce bruscamente; antes bien, se trata de un proceso paulatino, en el que el elemento apriorístico va diluyéndose, apreciándose cada vez con menor intensidad, aunque sin llegar nunca a desaparecer del método constructivo de las lenguas artificiales (la «artificialidad» consiste, justamente, en ese factor apriorístico que las acompaña). Mejor aún se entenderá que este proyecto anónimo contenga gran proporción de elementos apriorísticos si se recuerda que, según los datos de que disponemos, es la primera vez en la crónica de las LU que se intenta formar una lengua cimentada en varias naturales. No se puede exigir más a nuestro desconocido tratadista.

Y una última consideración de la «advertencia preliminar» que merece ser destacada:

Entre los diferentes sistemas gramaticales [posibles para nuestra lengua] no damos la preferencia al más simple, que sería el de reducir al menor número posible los artículos y pronombres haciéndolos indeclinables, como

\footnotetext{
32 Op. cit., págs. 234-237.
} 
los adjetivos, y conjugar los verbos [...] por medio de partículas auxiliares; porque concediendo a este orden el mérito de su mucha facilidad, le anteponemos el de hacer declinables todas las voces que pueden serlo, y formar las conjugaciones por medio de las diferencias de los finales en todos, o los más de los tiempos admitidos, para proporcionar así a nuestro proyectado idioma toda la riqueza y variedad que poseen los más aventajados de los existentes [...] (págs. 26-27).

Antes que por la facilidad de la nueva lengua, el anónimo se inclina por la riqueza y variedad como cualidades prioritarias que deben adornarla. Es una concepción de la LU que se encuentra aún muy alejada del pragmatismo que manifiestan otros inventores de lenguas ya en el siglo XX, como los ya aludidos J. López Tomás (1918) y Ch. K. Ogden (1930), quienes sacrificaron la «riqueza y variedad» de sus respectivos sistemas al criterio de la simplicidad - rayano en el esquematismo - para una mayor facilidad de aprendizaje $\mathrm{y}$, en consecuencia, una mayor difusión de los mismos.

2.2.2. Como se dijo más arriba, en el Bosquejo de gramática del idioma universal se presenta un proyecto concreto que cumple con las condiciones de formación de una LU expuestas en la primera parte del libro.

El a lfabeto de la lengua que se propone está integrado por cinco vocales y trece consonantes:

Vocales: i, e, a, o, u.

Consonantes: $\mathrm{b}, \mathrm{p}, \mathrm{f}, \mathrm{m}, \mathrm{d}, \mathrm{t}, \mathrm{n}, \mathrm{l}, \mathrm{r}, \mathrm{g}, \mathrm{c}, \mathrm{h}, \mathrm{s}^{33}$.

Las vocales son, como quedó dicho, «las cinco primitivas» del español, italiano y portugués, pronunciadas como en tales lenguas. Las trece consonantes elegidas son «sólo las precisas, de fácil pronunciación y usadas por todas las naciones» (art. 49); de ellas, las nueve primeras «se pronunciarán como se acostumbra en italiano, español, portugués, francés e inglés, en lo que no hay diferencias» (pág. 29), mientras que para el grafema $g$ propone el único sonido velar sonoro $/ \mathrm{g} /$, para la $c$ el velar oclusivo sordo $/ \mathrm{k} /$, a la grafia $h$ asigna el fonema palatal africado sordo $/{ }^{\mathrm{c}} / \mathrm{y}$, por último, el signo $s$ representará únicamente el fonema dental fricativo sordo $/ \mathrm{s} /$. El resto de

\footnotetext{
${ }^{33}$ Como nota curiosa, obsérvese que en el orden de exposición de los grafemas vocálicos y consonánticos el autor anónimo obra con un criterio que pretende ser lógico, al haber tenido en cuenta para su ordenación el punto de la cavidad bucal en que se produce su articulación (así, en las vocales va de las palatales a las velares, pasando por la vocal central, en tanto que las consonantes van de las «labiales» a las «dentales», pasando por las «linguales» $\mathrm{y}$ «paladiales»).
} 
las grafías consonánticas se desecha del alfabeto universal por muy variadas razones:

- Por tener sonidos «dudosos»: como la $v$, de pronunciación similar «a la $b$ en unas lenguas y a la $f$ en otras» (art. 50), o la $x$ y la $y$;

- por tratarse de grafemas «inútiles», al no expresar sonido alguno (como la $h$ muda) o al haber sido encomendada su pronunciación a otro signo del nuevo alfabeto (como la $k$ y la $q$ );

- por su escaso rendimiento funcional y por razones cacofónicas: la $\tilde{n}$ («por su poco uso y sonido nasal desagradable», $i d$.);

- por carecer de rasgos fónicos propios «en los más de los idiomas»: la $c$ y $z$ fricativas, que suelen confundirse con la $s$;

- por ser grafía «desconocida en las lenguas meridionales de Europa»: la $w$;

- por otras razones un tanto arbitrarias y subjetivas: la $j$, «por su sonido gutural y duro en unas lenguas, oscuro y difícil en otras» (id.);

- por motivos inexpresados: la $l l$.

Sobre la base del anterior conjunto de grafemas y fonemas vocálicos y consonánticos comienza a edificarse la morfología del proyectado idioma, en cuya exposición respetaremos el orden seguido por el propio autor:

No se reconoce más que la existencia del artículo definido (el indefinido se considera un numeral más), con tres géneros (masculino, femenino y neutro) y dos números (singular y plural):

$\begin{array}{lllll}\text { masc. } & \text { 'el' } & \text { bo } & \text { 'los' } & \text { bos } \\ \text { fem. } & \text { 'la' } & b a & \text { 'las' } & \text { bas } \\ \text { neutro } & \text { 'lo' } & \text { be } & \text { 'los' } & \text { bes }\end{array}$

Tres géneros se distinguen también en el nombre: masculino (para varones y animales machos; su terminación será siempre en $-o$ ), femenino (para mujeres y animales hembras; su terminación será en a) y neutro (para las cosas inanimadas y animales cuyo sexo no se acostumbre distinguir; su terminación será en $-e,-l,-n,-r){ }^{34}$. El plural

\footnotetext{
${ }^{34}$ El género neutro (en plural) se utilizará también «cuando se hable en general de hombres y mujeres, o de los machos y hembras de una especie de animales [...]; y cuando se designe uno de estos animales, cuyo sexo se ignore, se empleará en singular el sustantivo neutro» (Anónimo, op. cit., pág. 31).
} 
se forma añadiendo $-s$ a los nombres terminados en vocal, -es a los terminados en consonante. Algunos ejemplos de sustantivos del idioma universal:

$\begin{array}{ll}\text { 'hombre' } & \text { mano } \\ \text { 'mujer' } & \text { mana } \\ \text { 'hombres y mujeres' } & \text { manes } \\ \text { 'caballo' } & \text { caba } \\ \text { 'yegua' } & \text { cabes } \\ \text { 'caballos y yeguas' } & \text { musce } \\ \text { 'mosca' } & \text { arbe }\end{array}$

Para la formación del a djetivo se inclina por asignarle flexión de género y número, en concordancia con el sustantivo al que acompaña:

$\begin{array}{ll}\text { 'bello' (masc.) } & \text { belo } \\ \text { 'bella' } & \text { bela } \\ \text { 'bello' (neutro) } & \text { bele }\end{array}$

Una $-r$ final añadida al adjetivo expresará el grado comparativo, y la $-n$ el superlativo:

$\begin{array}{ll}\text { 'bueno/a' (positivo) } & \text { bono, }-a,-e \\ \text { 'mejor' (comparativo) } & \text { bónor, -ar, -er } \\ \text { 'buenísimo/a' (sup.) } & \text { bonon, -an, -en }\end{array}$

Los a umentativos y diminutivos se forman añadiendo al sustantivo y adjetivo las sílabas finales $t u$ y $t i$, respectivamente:

$\begin{array}{ll}\text { 'hombrón' } & \text { manotu } \\ \text { 'mujercita' } & \text { manati } \\ \text { 'caballitos' } & \text { cabotis } \\ \text { 'gordito' } & \text { grosoti }\end{array}$

Los numerales se forman según la clase a que pertenezcan:

a) Cardinales: los nombres de las unidades simples, así como los nombres de las unidades de decena, centena, millar y millón son monosílabos acabados en $-n$ :

$\begin{array}{ll}\text { 'uno' } & \text { un } \\ \text { 'dos' } & \text { duen } \\ \text { 'tres' } & \text { trin ... } \\ \text { 'diez' } & \text { ten } \\ \text { 'ciento' } & \text { sen } \\ \text { 'mil' } & \text { min } \\ \text { 'millón' } & \text { lon }\end{array}$


Los nombres de las decenas a partir de veinte se forman con los de las respectivas unidades seguidos de la sílaba te:

$\begin{array}{ll}\text { 'veinte' } & \begin{array}{l}\text { duente } \\ \text { trinte } \\ \text { 'treinta' } \\ \text { 'cuante... }\end{array}\end{array}$

b) Los ordinales añaden la sílaba $-u r$ al cardinal correspondiente (únur 'primero'), los colectivos añaden la terminación tie (sentie 'centena'), los múltiplos añaden al cardinal la sílaba be (duenbe 'duplo') y los partitivos se caracterizan por su final en -io (duenio 'mitad').

Los pronombres personales presentan la distinción de género $\mathrm{y}$ número hasta ahora vistos:

$\begin{array}{lccc} & \text { masculino } & \text { femenino } & \text { neutro } \\ \text { 'yo' } & \text { go } & \text { ga } & \text { ge } \\ \text { 'tú' } & \text { to } & \text { ta } & \text { te } \\ \text { 'él/ella' } & \text { lo } & \text { la } & \text { le } \\ \text { 'nosotros/as' } & \text { gos } & \text { gas } & \text { ges } \\ \text { 'vosotros/as' } & \text { tos } & \text { tas } & \text { tes } \\ \text { 'ellos/as' } & \text { los } & \text { las } & \text { les }{ }^{35}\end{array}$

Con el fin de conceder mayor «riqueza y flexibilidad» a esta lengua admite la declinación de los pronombres personales; de modo que una $i$ añadida después de la vocal indica los casos genitivo, dativo, acusativo y ablativo (da goi 'de mí', pa gais 'para nosotras', etc.) de las formas tónicas, mientras que una $u$ ubicada en la misma posición (gou 'me', gaus 'nos', etc.) denota la presencia de una forma átona.

Para formar los que nuestro autor denomina «pronombres posesivos» (en realidad, adjetivos posesivos, o determinantes), se agrega una $-i$ - a la consonante inicial de los pronombres correspondientes: gio 'mi', tio 'tu', etc. Por su parte, los «pronombres posesivos absolutos» (o pronombres propiamente dichos) se construyen añadiendo una $-n$ a los correspondientes adjetivos posesivos: gion 'mío', tion 'tuyo', etc. Respecto a la colocación de ambos tipos de posesivos en la frase, propone el procedimiento seguido en español: gio abo 'mi abuelo', frente a para gian 'madre mía'.

Para los pronombres demostrativos (que no se distinguen formalmente de los adjetivos demostrativos) adopta el sistema ternario del español: dro 'este', droi 'ese', drou 'aquel', con sus correspondientes femenino y neutro, y

35 «La voz go aplicada al pronombre de la primera persona del singular [y del plural], se ha derivado de su equivalente en latín ego. Para los otros pronombres se han elegido los monosílabos más parecidos a algunos de los de las lenguas principales» (Anónimo, op. cit., pág. 38 , nota). 
formas plurales. La flexión completa de género y número (salvo en $c o, c a$, $c e$ 'que', con sólo flexión genérica) también se observa en los pronombres relativos (coincidentes en su forma con los interrogativos):

$\begin{array}{lccc} & \text { masculino } & \text { femenino } & \text { neutro } \\ \text { 'cual/es' } & \text { col/es } & \text { calles } & \text { cel/es } \\ \text { 'quien/es' } & \mathrm{coi} / \mathrm{s} & \mathrm{cai} / \mathrm{s} & \mathrm{cei} / \mathrm{s} \\ \text { 'cuyo/s' } & \mathrm{cuo} / \mathrm{s} & \mathrm{cua} / \mathrm{s} & \mathrm{cue} / \mathrm{s} \\ \text { etcétera } & & & \end{array}$

Por último, todos los pronombres indefinidos (salvo si 'si' [?], alce 'alguien' y neme 'nadie', invariables; y ambos 'ambos', muos 'muchos', con sólo flexión de género) son, asimismo, 'declinables' en el singular y plural de los tres géneros:

$\begin{array}{lccc} & \text { masculino } & \text { femenino } & \text { neutro } \\ \text { 'uno/s' } & \text { uno/s } & \text { una/s } & \text { une/s } \\ \text { 'alguno/s' } & \text { ceouno/s } & \text { ceouna/s } & \text { ceoune/s } \\ \text { 'cierto/s' } & \text { serto/s } & \text { serta/s } & \text { serte/s } \\ \text { 'otro/s' } & \text { oto/s } & \text { ota/s } & \text { ote/s } \\ \text { etcétera } & & & \end{array}$

Los verbos se reparten en tres conjugaciones (cuyos infinitivos se reconocen por la terminación -ar, -er, -ir). Sus modos, tiempos, números y personas se distinguen según un sistema de flexiones construido de forma análoga al que ofrecen las lenguas románicas, «cuyo orden - explica el propio autor - hemos preferido al de las partículas auxiliares que los ingleses emplean en los tiempos futuro, condicional, optativo, potencial [...]; porque aunque conocemos la facilidad de este método, damos a aquél la preferencia por su mayor riqueza, y mejor aptitud para el lenguaje florido de la elocuencia y de la poesía, sin que le ceda en propiedad para el más severo que requieren las ciencias» (pág. 46). La cualidad que nuestro autor resalta de entre las muchas que presenta su sistema de conjugación verbal es la regularidad: «Todos [los verbos] serán regulares, y ninguno defectivo» (id.). Como muestra del sistema de conjugación seguido, ofrecemos las formas del presente de indicativo:

$\begin{array}{ll}\text { 'amo' } & \text { amo } \\ \text { 'amas' } & \text { ama } \\ \text { 'ama' } & \text { ame } \\ \text { 'amamos' } & \text { amos } \\ \text { 'amáis' } & \text { amas } \\ \text { 'aman' } & \text { ames }\end{array}$


De los restantes tiempos simples sólo consignaremos la primera persona del singular:

\author{
INDICATIVO \\ Pretérito imperfecto: amoi 'amaba' \\ Pretérito indefinido: amó 'amé' \\ Futuro imperfecto: amió 'amaré'
}

IMPERATIVO

Presente: amae 'ama tú'

\title{
CONDICIONAL
}

Futuro hipotético: amio 'amaría'

\author{
SUBJUNTIVO ${ }^{36}$ \\ Presente: amou 'ame' \\ Pretérito imperfecto: amuo 'amase' \\ Futuro imperfecto: amoú 'amare'
}

Las formas no personales del verbo son: infinitivo amar 'amar'; gerundio amando 'amando'; participio presente amante 'amante'; participio pasado amato 'amado'.

Con el auxilio del verbo ader 'haber' se construyen los tiempos compuestos: ado amato 'he amado', adoi amato 'había amado', etc., reservándose un segundo verbo auxiliar (eser 'ser') exclusivamente para las construcciones pasivas: esó amato 'fui amado'.

La categoría del adverbio se divide en diez clases semánticas diferentes, cuyos elementos léxicos simples observan la norma del monosilabismo, por una parte, y por otra (adoptando un procedimiento característico de los sistemas $a$ priori) presentan una terminación uniforme en el interior de cada clase:

La importancia de estas voces [adverbiales], y su frecuente uso, nos han inclinado a que todas ellas sean monosílabas, y que las de cada clase (exceptuadas las compuestas) tengan una misma terminación, a fin de conocerlas más fácilmente (pág. 68).

El autor nos ofrece casi dos centenas de adverbios (incluyendo los 'declinables', es decir, aquellos que admiten formas del comparativo, superlativo y diminutivo) de la nueva $\mathrm{LU}$, por lo que, junto con las preposiciones $\mathrm{y}$ conjunciones, es una de las categorías verbales que se muestran más acabadas en la obra. Algunos ejemplos de adverbios:

${ }^{36}$ Aquí se considera el modo subjuntivo, pese a que en la primera parte del libro se había afirmado: «Se podrá si pareciere bien suprimir el modo subjuntivo, que por poco necesario no tiene algún idioma» (Anónimo, op. cit., art. 53). 
- de tiempo: nai 'ahora', dai 'ya', siei 'siempre'...

- de lugar: ier 'aquí', ber 'hacia', far 'lejos'...

- de modo y calidad (donde se incluyen los acabados en -mente, terminación que equivale a la sílaba -li): biel 'bien', sil 'así', fideli 'fielmente'...

- de cantidad: mиo 'mucho', suo 'bastante', nao 'nada'...

Las preposiciones se atienen también a los límites del monosilabismo y a la uniformidad desinencial (en -a). El autor, frente a otras opciones que le ofrecen gramáticas de lenguas extranjeras, no se aleja de la Academia Española a la hora de escoger los elementos que, en número de dieciséis, integran esta clase de palabras: $a$ 'a', $d a$ 'de', na 'en', biá 'por', $p a$ 'para', coá 'con', fra 'entre', etc.

Las conjunciones quedan reducidas a catorce, observando el monosilabismo consabido y la terminación en - $e$ : $e$ 'y', ne 'ni', cué 'que', oé 'o', me 'pero', he 'aunque'...

Si bien el anónimo reconoce los escollos que se presentan en la invención de nuevas interjecciones («conocemos efectivamente la dificultad de que todos los hombres expresen con determinados sonidos sus repentinas sensaciones de alegría o tristeza, placer o dolor, admiración o espanto», pág. 75), finalmente se decide a componer una relación de palabras exclamativas - hasta una treintena - con su correspondiente significado: ao, ia, urra (denotan alegría), ea, sus, hir (sirven para llamar), etc.

Un breve párrafo dedicado a ensalzar la fecundidad léxica de la lengua propuesta ${ }^{37}$ cierra este apartado consagrado a la exposición de sus características morfológicas, y que hemos tratado de compendiar en las páginas precedentes. Con tales indicaciones se da por finalizado el bosquejo del nuevo idioma:

Completo ya lo que nos habíamos propuesto decir sobre la analogía, no trataremos de las demás partes de la gramática, por no creerlo necesario; pues para dar idea de la sencillez, laconismo, perfección y belleza que puede alcanzar la lengua universal bien combinada por sujetos idóneos, basta con este defectuoso ensayo, en el que tal vez hemos pecado de difusos (pág. 77).

En las páginas finales del libro se insertan dos textos con sus respectivas traducciones interlineales en la recién nacida LU; reproducimos a continuación unas líneas de la correspondiente a un fragmento del Quijote:

\footnotetext{
${ }^{37}$ «El idioma universal deberá aventajar a todos en esta preciosa propiedad, por poseer [...] la de que todos sus verbos tengan participios activos y pasivos adjetivos; la de que de la mayor parte de los adjetivos puedan nacer adverbios; la de que todos aquellos tengan los tres géneros, y fácil aplicación del aumentativo, diminutivo, comparativo y superlativo [...] (Anónimo, op. cit., pág. 76)
} 


$$
=79 .=
$$

\section{TRADUCCION}

\section{DE UN FRAGMENTO DEL QLIJOTE.}

Capítulo LXVI.=Que trata de lo que rerá el que lo leyere Capite $66 .=C e$ trate da lcu ce bidié le cué leu legé். \& lo oirá el que lo escuchare leer.=Al salir de Barcelona voloé leu cudié le cue leu listeú leger $=A$ be esir da Barcelona bolvió 1). Quijote á mirar el sitio donde habia caido, y dijo; aquí bè Don Quijote á mirar be site uer adei cadeto, e disé; ier fué Trova, aquí mi desgracia y no mi cobardía se llevó mis alcanesè Troia, ier gie inluce e no gie inabie seu portè gles asezadas glorias: aquí usó la fortuna conmigo sus vueltas y revueltas: cates glories: ier usè fórtun coá goi lies turnes e returnes: aquí se oscurecieron mis hazañas: aquí finalmente cayó mi ventura. ier seus oscurès gies fasimes: iè láteli cadè gie luce para jamas levantarse. Oyendo $10^{\circ}$ cual Sancho, dijo: tan de pa mai lebarseu. Audendo leu cel Sancho, disè: tao ese valientes corazones es, señor mio, tener sufrimiento en las desgrada balentes cuores, gio sior, tener suferio na bes inlucias, como aleeria en las prosperidades: y esto lo juzgo por mí ces, soel gáudel na bes prosperies: e dre leu iudico biá goi mismo, que si cuando era gobernador estaba alegre, agora que soy memo, cuè siè cuai esè gobernor esei gáudie, nai cuè eso rscudero de á pié, no estoy triste: porque he oido decir, que esta escutaro da pede, no eso triste: praè ado audito diser, cuè drai que llaman por ahí fortuna, es una muger borracha y antojadiza, y ca nomines biá dier fórtun, ese una mana ebriosa e caprisa, e sobre todo ciega, y así no ve lo que hace, ni sabe á quien derriba, soá tuo saeca, e sil no bide dreu ce fase, ne sabe a cei diruse,' ni \& quien ensalza. Muy filósofo estás, Sancho, respondió D. Quijone a cei esalte. Mo fllosofo eses, Sancho, repondè Don Quijo1..): muý á lo discreto hablas, no sé quien te lo enseña. Lo que te te, mo a be discrete parla, no sabo cei te leu dosere. Leu ce tou 
3. Nuestra glosa final debe ir encaminada a insistir en el lugar de honor, hasta ahora nunca señalado, que a esta obra corresponde en la historia de los proyectos habidos en Occidente para la formación de una LU. Este librito de apenas 80 páginas, publicado en 1852 sin encabezamiento de autor y atribuido desde 1861 a Pedro López Martínez (y un siglo después, por un error de interpretación, a Pedro Martínez López), constituye el primer ensayo conocido de una LU que, en el marco de los sistemas elaborados $a$ posteriori, se sirve de los elementos comunes de varias lenguas europeas (latín, italiano, español, francés, inglés y alemán) para construir el léxico de la nueva lengua general, del cual nos ofrece en este esbozo unas «500 voces o pocas más» (pág. 27). La obra que hemos analizado puede ser considerada, por tanto, la primera muestra de una larga serie de proyectos (como el Volapük o el Esperanto) que durante la segunda mitad del siglo XIX nacieron al dictado de un nuevo criterio, que pretendía ser realista, neutral y ecuánime: el de la internacionalidad. Esta propuesta española se adelanta, pues, en al menos seis años (quizá en decenios, puesto que la idea le sobrevino al autor en 1824, según propia confesión) a la que hasta ahora se consideraba pionera en la construcción de una LU a partir de los elementos léxicos de varias lenguas naturales: la denominada Pantos-dimou-glossa, de Lucien de Rudelle (1858).

Desde esta perspectiva se trata de un proyecto de gran modernidad, por su procedimiento tan alejado del que utilizan los inventores de lenguas $a$ priori, esencialmente filosóficas y sin sustento en las naturales. Como avanzada es la idea que también se defiende en sus páginas, respecto a la propuesta de constitución de una Junta de eruditos que se ocuparía de la adopción e implantación progresiva de la LU (diseñada en primer término por un «literato laborioso»): La cuestión del idioma internacional no se ciñe ya a los estrechos límites y a las escasas fuerzas de un solo individuo, el propio inventor del idioma, sino que se concibe ya con una gran dosis de pragmatismo, como un problema que deben solventar, por este orden y básicamente, los hombres de ciencia y las autoridades políticas.

Destacables nos parecen, asimismo, sus sugerencias relativas a los pasos que deben andarse en la elaboración y propagación universal del nuevo código, que coinciden puntualmente con las etapas que sociolingüistas de nuestra época han propuesto para llevar a cabo una eficaz planificación lingüística en los ámbitos correspondientes.

No obstante, junto a estos rasgos novedosos, es de justicia reconocer que en el autor anónimo pesa aún el lastre de rancias ideas, como el convencimiento de que su lengua terminará por imponerse sobre las vigentes, aniquilándolas y suplantándolas. O la todavía considerable medida de apriorismo que preside la formación del léxico: los vocablos propuestos a veces se 
inventan sin más, sin que pueda hallarse paralelismo formal con ninguna de las seis lenguas que sirven de cimiento, porque en no pocas ocasiones las pautas logicistas (la aspiración al monosilabismo, a la uniformidad en la terminación de las clases de palabras...) se imponen sobre la realidad y la «sinrazón» de las lenguas.

Podría añadirse, por último, en detrimento de esta obra que en ella no se nos presenta más que un esbozo de la morfología, descuidándose $\mathrm{o}$, mejor, eludiéndose el trascendente capítulo de la sintaxis, de la que escuetamente se nos dice que habrá de ser «sencilla, uniforme e invariable» (art. 63). Objeciones ciertas todas ellas, pero que no deben ocultar el valor que este libro anónimo (curiosamente ignorado por los minuciosos cronistas de la LU Couturat y Leau) encierra, por tratarse del primer intento conocido de construir una LU basándose en el principio de la internacionalidad de los elementos léxicos. 